\title{
Study of the Heritage of Korkyt in the Turkic World
}

\author{
Tynysbek A. Kongyratbay ${ }^{1}$, Maira S. Sultanova ${ }^{1}$, Nartai S. Bekmoldinov ${ }^{2}$, Bolat Zh. Ospanov ${ }^{3} \&$ Kalzhan T. \\ Kongyratbay $^{4}$ \\ ${ }^{1}$ Kazakh State Women's Teacher Training University, Almaty, Kazakhstan \\ ${ }^{2}$ Kazakh National Academy of Arts named after T. Zhurgenov, Kazakhstan \\ ${ }^{3}$ The Korkyt Ata Kyzylorda State University, Kazakhstan \\ ${ }^{4}$ Kazakh National Pedagogical University named after Abai, Kazakhstan \\ Correspondence: Tynysbek A. Kongyratbay, Kazakh State Women's Teacher Training University, 99, Aiteke bi \\ street, Almaty city, 050000, Kazakhstan, Tel: 7-775-523-1515. E-mail: tynysbek55@mail.ru
}

Received: January 19, 2015 Accepted: June 12, 2015 Online Published: July 6, 2015

doi:10.5539/ass.v11n21p55 URL: http://dx.doi.org/10.5539/ass.v11n21p55

\begin{abstract}
This article studies the outstanding historical personality of Korkyt, his heritage in music and literature. Researches related to Korkyt, conducted by Turkic scientists analyzed, including popular tales and myths, "Korkyt baba's book". There were new suggestions to find out him as a zhyrau and his musical heritage. Especially a complex issue whether the real existence of Korkyt was true or he was only folklore personage and about the real period of Korkyt's life has been aroused based on ethno geographic uprising of the oghyz tribe.
\end{abstract}

Keywords: Korkyt, myth, epos, song, kui, archaeology, ethnology, folklore study, history of literature, music studies, genetic, polistaging, typological, mythical studies

\section{Introduction}

Nowadays there are many scientific researches about Korkyt, who was popular among Turkic culture within one century. According to those works, historical and cultural relics related to Korkyt's name have been pointed out differently. The first information about Korkyt can be found in "Genealogy of Turks" (Kononov, 1958) by the ruler of Khiva Khanate Abu al-Ghazi Bahadur, and further in works of prominent scientists such as V. Bartold, V. Gordlewskii, I. Kastanie, V. Zhirmunskii, K. Inostrantcev, A. Kononov, A. Samoilovich, P. Spiridonov, A. Yakubovskii, G. Arasly, M. Takhmasib, Kh. Koroghly, O. Gokiyai, M. Yergin, M. Kepryulyuzade, Sh. Ualikhanov, M. Auezov, A. Zhubanov, A. Marghulan, A. Konyratbayev and many other Turkish, Azerbaijani, Turkmenistani and Kazakh researches.

It is confident that one of the Kazakh prominent scientists M. Auezov considered Korkyt as a myth personage among Aldar-Kose, Kozhanasyr and Asan-Kaighy (Auezov, 1948). In addition, academician A. Zhubanov stated the content of myth about Korkyt's distinct birth (Zhubanov, 1942). Among many Kazakh researchers, A. Marghulan and A. Konyratbaev were the first who paid a lot of attention to the personality of Korkyt in history, to his art and heritage in literature. One of them left valuable heritage about continuers of kobyz custom, which first started from Korkyt (Marghulan, 1975), and another one translated one of the important work "Korkyt baba's book" into Kazakh language (Konyratbaev, 2008). Exploring deeply the myths about Korkyt, he concluded that all Korkyt's attempts to escape the death were the philosophical results of clash between shamanism (people are undying) and Muslim (the death is obliged to human) (Konyratbaev, 1991). It will not be a mistake, if we say that this period is the beginning for the further researches about Korkyt in Kazakh science.

\section{The Main Part}

In recent years in Kazakh folklore studies the number of superficial and biased understandings is increasing because of not paying serious regard to the theoretical axioms of the last centuries. This cause to the lack of academic degrees of thousands researches: there are new inclusions, but also there is now absence of weaknesses. Therefore, the lack of studies on the theme of Korkyt's heritage is a huge issue. The issues about Korkyt's cemetery, myth and popular tales, well-known "Korkyt baba's book", the connection of its content with Kazakh epos, the relation of onomastic names to Syrdarriya, the origin of Korkyt, the period of his life, works in music, even consideration of Korkyt as a not a real person, but as the character of folklore have been pointed out. 
From the scientific aspect, general Turkic issues about Korkyt have been studied in archeology, ethnology, folklore studies, history of literature and music studies, and have been cognized from the genetic, typological and mythological aspects.

The majority of researches about Korkyt have less novelty than compilation: all of them recite the content of myth, which is known to the entire world, repeating the entire database again and again. Many myths have local characteristics because of the names of historic people and place of that region. But, consideration of myths as a whole history leads to escaping all the theoretical information of folklore studies which have been gathered in more than three century.

Myth is not a historic clew, it is artistic phenomenon, which is formed by historic cognition and has an aptitude to changes. The arrangement of several worldviews can be found only in one myth. This refers to the weakness of considering the personage of the myths as historical people (such as Karabura) and stating the myth as a historical event without noticing the philosophical feature of the content. However, the number of people who are finding history and myth as an equal phenomenon, considering the myth as a clue to the history is increasing day by day. It is not allowed to consider it as a scientific cognition.

For instance, the myths related to Korkyt's name are changing, as time passes. Many scientists added the new plot to the content of myths: Velyaminov-Zernov (1889), P. S. Spiridonov (1909), A. Divayev (1992), N. Dzhetpisbayev (1899). For more information, many researchers point out that Korkyt used to travel with his Zhelmaya as it is obvious in Kazakh myths about Asan Khaighy. It is understood as a recent artistic phenomenon- contamination, integrating the plot of one myth to the other, but not as a cyclization. In this case, the speaker of the myth who updated the content plays an important role.

If to study deep, the plot of these two myths are quite different. While Asan Khaighy was looking for heavenly place for living, Zheruiyik, Korkyt wanted to find a place where he can escape from the death. There are two different philosophical understanding in these two myths.

Most researchers on Korkyt's theme refer to the previous works, which are not relevant for modern moral, without analyzing recent scientific works. It will be useful if they have something to add to the ancient ideas, but there is no use for science of reciting well-known stories with no critical opinions.

Most of them do not consider Korkyt as a rational scientific cognition, but as a part of mystery world, not paying attention to his historic personality, origin, period of life and heritage in literature and culture. Holding on the state "Considering dead is not being dead, and alive doesn't mean being alive" is not a feature of scientific cognition. Especially it can be find out in identification of the origin of the etymology of the word "Korkyt" (Kaskabasov, 2011). It is not possible to cognize the historic people relying on only feelings. Because of this, all historical and genetic clews and scientific suggestions should have been rethought using hermeneutic methods in today's cognitive issues.

At first, there should be clearness in the issue whether Korkyt is the personage of legend or myth itself. Because V. N. Basilov (Losev et al., 1982), S. Kaskabasov and other scientists consider Korkyt as a personage of myth in world mythology, as in works of Velyaminov-Zernov, P. Spiridonov, A. Divaev and others Korkyt is a personage of legend.

According to the folklore theory, a legend is a genre related to a specific and local place. Thereby, the main contradiction is stating a charatcer of legend in the world of mythology. In Kazakh legends, Korkyt is stated as a holy character of legends. This fact leads to different opinions about the period of Korkyt's life. The scientific basis of majority of them is precarious. In addition, there is some kind of researchers, who made his period only relying on conjectures. Because of it, there is confusion in encyclopedias, some of them relate Korkyt's period to V-VI centuries, sometimes VII-VIII, and IX-X centuries (Gabitov et al., 2004).

In accordance with it, there is always a question mark about his right period of life, and about the main clues in the history that refer to his existence at real time.

Korkyt was from oghyz tribe, he was outstanding zhyrau (not a performer of kui) and a wise person. There are also many researches about oghyz tribe. Among them works of S. G. Agadjanov play an important role (Agadjanov, 1973). He deeply investigated the history of this tribe in IX-X centuries and their ethnography. The main location of oghyz tribe in ancient Turkic era is known as Altay, including Zhetisu in VII-VIII centuries, the lower reaches of Syrdariya in IX-X centuries, Amudariya (Turkmen) in X-XI centuries, at the seaside of Black sea (Azerbaijan) and Anadoly (Turkey).

Also, some researchers give information about Korkyt's period of life, saying that he lived in V-VIII centuries, not taking into consideration the uprising of oghyz tribe in above-mentioned centuries. Supporters of this theory 
cannot prove it with scientific-historical information. Therefore, they did not even notice that according to them Korkyt lived in the period of "Kultegin", "Tonukok" in ancient Turkic era.

Scientists relating Korkyt's period of life to V-VIII centuries do not pay attention to the additional materials about oghyz tribe. One of them is "Encyclopedia of Turks" by M.Kashgari. Based on this book, there can be found different syllable words of oghyz dialect. The book included names of famous people of oghyz tribe: leaders of nation, warriors, even names of beautiful women, except Korkyt's name. The fact Korkyt's name cannot be found in the book proves that he did not live in V-VIII centuries. In ancient Turkic period, oghyz tribe did not inhabit in Zhetisu or at the seaside of Syrdariya, but in the area of Altay.

The conclusion is that M.Kashgari did not know Korkyt, because they lived in different period and different places. Majority of information about oghyz tribe in his book is the period of oghyz in Zhetisu. At this period Korkyt's name was not familiar to people.

That is why we can say without any doubt that Korkyt lived in IX-X centuries in the center of oghyz tribe Zhankent, located in the lower reaches of Syrdariya. According to archeological works of K.Baipakov people started to inhabit Zhankent in about X century, which proves historical theory about Korkyt.

As mentioned above, according to Abylghazy's works, Korkyt was real man, not a chatracter. In memorials of Rashid-ad-Din, names of warriors of oghyz tribe are stated with the period of Korkyt's life (Rashid al-Din, 1952). In "Korkyt baba's book", Korkyt was described as a poet from oghyz's kaya tribe (sometimes bayat). The common information from above works said that Korkyt was always mentioned in the center of oghyz tribe.

Nowadays there is also another opinion about the existence of Korkyt as a real person, which claims that he was personage of myth. In previous century, the existence of Korkyt was explained as a character of legend, which is being discussed among today's scientists. Researchers, which rely only on the folklore information, do not take into consideration genealogical clews and hesitate about historical existence of Korkyt. However, philosophers paying no regard to the legends stay on that Korkyt existed in real life. The last point appeared in XIX century, folklore researchers do not pay attention to this experience as it used to be criticized in previous centuries. In 80 -ies of XX century scientist Khalyk Korugly pointed out to the ethnic history of ogyz tribe and wrote "Heroical epos of oghyz tribe". He investigated ethnic history and uprising of west and east oghyz tribe and came to conclusion that Korkyt was just a character of folklore (Koroglu, 1984). Kazakh scientists S.Kaskabasov and E.Tursynov continued this idea.

Materials about Korkyt's ethnical and geographic origin of mid centuries insist on the fact that he was character of folklore and prototype of history. It is just easing the scientific cognition, relied on only folklore materials. It is obvious that it will not lead to true scientific cognition, if we do not take into consideration historical and folklore information in literature, just relying on myth. Because of it the studies about Korkyt cannot be improved, reciting events that are known to the world. Scientific suggestions based on new methodological researches and work directed to discovering the connection of Kazakh, karakalpak, Turkmen, Azerbaijan and Turks of Anadol stayed at one place. It is one aspect of barrier to make close all Turkic nations.

Another question is what kind of cognitive categories and methods should be taken into consideration to study and promote heritage of Korkyt.

First of all, attention should be paid to fact that Korkyt was not just a folklore character, but he was a historical person. The history and culture of Turan (Kazakhstan, Kyzylorda region, Karmakshy), where his cemetery was found, gives a lot of information. Evidence related to the mid centuries have not been investigated completely. The most efficient way would probably be to explore the history of ethnical geographic uprising of oghyz tribe in early and mid centuries (not antique time) and historical events that appeared in "Korkyt baba's book".

Secondly, Korkyt is not a character to be studied just in Kazakh history. Turkey and Azerbaijan scientists also did important works. Even graves of Korkyt were found in above-mentioned countries. How the character of Korkyt can be valued in those conditions. It will not lead to scientific cognition if we consider that each country has its own Korkyt. It is characterized as a main weakness from scientific point of view. If we study information about Korkyt in Kazakh, Azerbaijan and turkey folklore relating to the ethnical uprising of oghyz tribe, we can distinguish the period of life of Korkyt.

Also, there is another opportunity to study with the usage of hermeneutic method. To achieve good results all information about Korkyt must be studied and analyzed one more time from new point of view. The personality of Korkyt should be divided from historical-cultural process and studied not in the myth or legend sphere, but as a real existed historical person. This is the main reason of appearance of Korkyt in the mid of oghyz tribe in "Korkyt baba's book". 
There is a big discussion relating to musical heritage of Korkyt, as people of Azerbaijan claim him as a zhyrau with his gopuz, whereas Kazakh people insist on kobyz. There also people who perform Ykylas's kui naming Korkyt as an author of them.

It does not mean that we should not pay attention to the musical heritage of Korkyt in other Turkic nations. Unfortunately, this aspect is not studied in scientific way and his kuis are studied not by scientific methodological researchers of music, but by performers of kobyz.

It is explained, according to the interests towards Korkyt's name. However, it will be useful to science if we study relying on historical-cultural evidence and scientific cognition. In this case, it is appropriate to put scientific demands along studies.

According to scientists, kobyz is a string musical instrument, which has a bow. These researchers claim that if instruments played with the help and clicking by fingers are old type, whereas string instruments with bows appeared much later. Therefore, in the period of Korkyt melodies that played by kobyz were not formed as a kui. There is no evidence that oghyz tribe has instrument with bows. Moreover, from the ancient oghyz writings as "Korkyt baba's book", instrument of Azerbaijan people kobyz (gopys) did not have a bow. It is one aspect.

Secondly, there was a tradition to sing an epos with the help of kobyz, but not to perform a kui. In epos, we can find poetical content and plot. For this reason, they were understandable for all people.

Kui is a musical instrumental performance. M. Kashgari, who named percussion and string instruments, but did not mentioned about instruments with bow. In addition, musical performance as kui was not named in his work. Among inhabitants of central Asia kui genre appeared in XVI-XVII centuries, and development of it is only in XIX century. Taking into consideration these facts we can say that in the period of Korkyt's life there can be neither performance of kuis nor instruments with bows in cultural life of oghyz tribe.

People who intend Korkyt as an author of kuis are today's performers. Performers of kobyz are not researchers. They can just perform notes without change. In this case, we can compare them with the drama actors. They can only act as the character of the history as it is written by the author without any change in it. One reason of dismissive opinions related to Korkyt's heritage in music can be this point.

Musical heritage of Korkyt known to the Kazakh, Turkmen, Azerbaijan and anadoly is well spread among Kazakh people. There is absence of original kobyz melodies of Korkyt in above-mentioned nations. Even Kazakh people do not have them in origin. The art of zhyraus starts from early period oghyz tribe and continues in Kazakh culture, but they are not complete saved in Kazakh music. Because there is uncertainty about the period of his kuis, and the performers who transferred them up today. Even there is no any evidence of his kuis in mid centuries. It is well known, that fragments of korkyt's kobyz melodies were recorded from Nyshan abyz, a citizen of Kyzylorda, Kazakhstan. Therefore, they were published as Korkyt's original heritage (Korkyt, 1987). This publication leads to biased information. The themes of those musical artworks ("Bashpai", "Targhyl tana") are mostly about general life, and do not coincide with the themes of heroism and bravery as where during the oghyz tribe. It will be faithful to say that those low artistic, with simple construction and not completely finished fragments of works cannot belong to Korkyt, who lived in IX-X centuries, but to Nyshan Shamenuly from XX century. Because those performances played in kobyz will not increase the authority of Korkyt's heritage, but even will decrease. There is lack of changes of mood, which suppose to the chromatic system and intonation of tune, which is specific for kobyz melodies. It will be shameful if his works are seen in the international arena and are noticed by music researchers.

There is a huge space between Korkyt's period and Nyshan abyz's life continuing for centuries. It is known, that oghyz tribe during the period of Korkyt's life in the IX-X centuries moved to the seaside of Amudariya, and therefore what kind of events can connect the two periods with the space of thousands of years. At that time the history, culture, and even inhabitants of that area changed. It is not our task to find out new thing from nothing, and we should value what we have, investigating that aspect from different points, because scientific cognition must be relied on true historic evidence.

In Kazakh and Turkmen, music kuis on kobyz and sybyszy appeared in XIX century. Ignorance of some performers can be seen when they presented some works as "Korkyt", "Kazan", "Konyr" as the heritage of Korkyt, whereas they belong to Y. Dukenuly and have been published in "Gylym" publishing in 1964.

This fact can give nothing to scientific truth and cognition. There is no evidence that it belong not only Nyshan, but also works of Y. Dukenuly to Korkyt.

Therefore, there is a question about real musical heritage of Korkyt. Probably, when it comes to Korkyt's musical heritage his aspect as a zhyrau must be on the first place. In "Korkyt baba's book" his personality is 
described as a zhyrau with his kobyz. Kobyz was used as an instrument to accompany poems when there was no instrumental music.

The tradition to sing poems was one of the main customs of Turkic people. For instance, there was popular an epic tune in low register among Khakassia and Tuva. This custom found its continuation among Kazakh people at the seaside of Syrdariya (Karmakshy) up today. This type of singing is also known in Turkmen music. In our country, it is called "anyrama", and they name it as "zhuki-zhuki".

This above-mentioned fact should be used as evidence in studying Korkyt's works. In ancient time, most of epic poems were performed with accompanying of string instruments, and only then, instruments with bow were used. According to Sh. Ualikhanov the last performer in Kazakh culture, who song a poem with the help of kobyz was Zhanak zhyrau, but in karakalpak culture, it has its continuation.

So, the tradition of "anyrama" in Karmakshy, where Korkyt was buried, singing poems is phenomenon of ancient Turkic period. It must be the beginning to study Korkyt's musical heritage. It is also important to learn the custom of singing poems on the area of Syrdariya, finding connections in the music tradition of anadoly, Turkmen and Azerbaijani people. This can be one of the methods to interconnect the culture of Turkic people in Altay.

Also, we can add that Korkyt's works have been transformed and seen in kobyz melodies of Ykylas. The names such as "Korkyt", "Kazan" say itself about the evidence. It is doubtful that Korkyt named his kui after his own name. And continuers of this tradition could present complex, adaptable to mood changes and high level artistic performances. Also it doesn't coincide the origin of the kui "Kazan" with the conquest of Ivan Grozny, but can be found in "Korkyt baba's book". It is connected with the name of warrior and khan of oghyz tribe, Kazan. Probably, the origin of Ykylas's performances lies in the period of oghyz tribe. But this kind information has not been saved in Kazakh culture and history.

In order to investigate the ancient Turkic characteristics of kobyz melodies in Kazakh culture there should be done comparative-typological researches. In this case we can underline the similarity of Ykylas's works special for kobyz and melodies of Turkmen people special for "karga tuidik" (sybyzgy) such as "Kiyamet" (Uspenskij \& Belyaev, 1979). And these researches demand further continuations.

It is time to analyze the period of Korkyt's poems and consisting information about Kazakh history relying on "Korkyt baba's book" and ethno historic uprising of oghyz tribe. Also it is important to find out the period of each fragment from the poem. Formation of scientific system of researching historical and cultural information in poems of Kazakh people about bravery is on its developing way (Kongyratbay \& Kongyratbay, 2013).

Above mentioned materials were studied by Kh. Korughly and he claimed that epos of 1-4, 7-8, and 12 lines first appeared during the period when oghyz tribe inhabited the seaside of Syrdariya. But many Kazakh scientists did not pay attention to this aspect. Only A. Konyratbaev, taking into consideration that fact, connected the poem of 12 lines with the formation, development and disappearing of oghyz tribe, and named this kind of poem not poem of tribe, but poem of nation.

Also, it is important to pay regard to the names of place and people that can be found in "Korkyt baba's book". Before some opinions related to the names such as "Baybura bek" (Baybori), "Bamsi Beyrek" (Alpamys) and others have been appeared. Some names can be found in Kazakh epos, which has been changing as following: Banu-Barshyn-Gulbarshyn. Sometimes it was used as hydronym (Barshyndariya), sometimes as anthroponym (Barshyn) and sometimes as oikonym (Barshykent). As this example, the name of river "Tana" was used. It is founf in antique Greek writings as "Tanais", the equivalent of Syrdaryia (Kongyratbay, 1996).

This kind of analyses gives an opportunity to find the connection of Korkyt's epos to Turkic, especially Kazakh people. And it is almost time to present academic publications of Korkyt's epos. For it, we have enough material and specialists.

\section{Conclusion}

Nowadays "Korkyt baba's book" is well known to the whole world, but Korkyt is familiar only among Turkic nations. Therefore, the main task of scientific cognition is to make Korkyt's name become popular in the world. To achieve this aim it is necessary to organize international scientific conference relating to Korkyt and his works. The important role played the conferences taken place in Turkey "Dede Korkut ve Gegmisten Selecege Turk Destanlari" Uluslararasi Sempozyumu (2011), and scientific-practical conference "Great melody of steppe and Korkyt's music" in Kazakhstan. Reconstruction of Korkyt's campus, which is located in Karmakshy, Kizilorda, Kazakhstan also plays an important role. 
But all those organized scientific conferences do not pay regard to bringing closer all Turkic nations through Korkyt. They are not comparable with the conferences organized in 1955-1958 on the theme "Manas", "Alpamys" during the soviet period. All published materials are still actual today. And it will be useful if all actual themes related to Korkyt can be found too. Only in this case the necessity in conferences can be defined. All international meetings must be done not because of the plans, but because of mental cognitive necessity of actual issues. Without it we are going to stay in one round reciting one and the same compilation. Because of this reason, it is almost time to widen scientific studies about Korkyt and to pay attention to the cognitive issue.

The more scientific researches have been done, the more demands to collecting are rising. One way out of this issue is to publish an encyclopedia "Korkyt". All information and material related to Korkyt's name should be included in this encyclopedia. It will be in a world level if we publish it in three languages- English, Kazakh and Russian. It is going to be the first scientific cognitive publication in the entire world.

Also there is a huge importance of stating piece of art about Korkyt. It is an appropriate time to perform a play, musical work and artistic movie. In Azerbaijan, a movie "Dede Gorgud" was shot during the Soviet Union, and several years before a play by Turk playwriter was presented in accordance with international scientific conference in Kyzylorda.

Nowadays the character of Korkyt can be found in many musical works, as an example we can name T.Konyratbay's symphonic poem "Korkyt baba". This poem was written for classical and symphonic orchestra and can be found as one of piece of art to make popular Korkyt's name to the entire world. It is almost impossible to present performances of folklore or national instrumental orchestras such as "Otyrar sazy" or "Kurmanghazy" abroad. It makes possible to listen to such kind of works, but not perform. Because, they do not have our national instruments such as dombyra, kobyz and sazsyrnay. Only compositions of classical symphonic orchestras can be performed abroad.

Another step must be done is to publish a journal "Korkyt" in international level. Vatican and Drezden variants of poems "Kitabi dadam Korkyt" are familiar to different nations of the worlds, and now comes the time for musical works.

In last years in international Kazakh-Turk, university after Akhmet Yassawi has been publishing a journal "Turkology" in Turkistan. The journal has a high level of international standards and is well spread among CIS nations. It is required to publish "Korkyt" journal in such level. It is discussed theme whether Academy of Turk or university named after Korkyt will do this task. It will be relevant if the organization of "Turksoy" takes responsibility.

Also all heritages common to Turkic people such as "Korkyt baba's book" and "Korughly" should be presented. They are the beginning of the epic works that makes close all Turkic people. All ethno historic information that mentioned works serve are not investigated completely. As an example, the antique name of Syrdaryia, which is presented in "Korkyt baba's book", is "Tanais", and the name of "Shambil bel" in "Korughly" has the connection with "shamba" trees in Antalya's mountainous area. Completely investigating such kind of similarities, we have an opportunity to find historical and cultural connections. It will become an important work in studying mental culture of inhabitants of the seaside of Syrdariya, if we publish all above-mentioned works in academic level.

All in all, the content of the main issues that has been done and needs to be done are mentioned above. The important thing is to pay all effort in order to present Korkyt as a historic prototype, not as just a person in the history of Kazakh, Azerbaijan and Anadol Turks.

\section{References}

Agadjanov, S. (1973). Seljukids and Turkmenistan in the XI-XII centuries. Ashgabat.

Auezov, M. (1948). Tales. History of Kazakh literature (Vol. I). Folklore. Almaty.

Divaev, A. (1992). Gift. Almaty.

Dzhetpysbaev, N. (1899). Korkyt Aulie: Turkestan statements. Tashkent.

Gabitov, T. et al. (2004). Kazakhstan. National encyclopedia (pp. 57-58). Almaty.

Kaskabasov, S. (2011). Kazak folklorundaki korkut anlayisi. In Dede Korkut ve Gegmisten Selecege Turk Destanlari Uluslararasi Seтровуити (pp. 15-22). Ankara.

Kononov, A. (1958). Geneology of Turkmen essays of khan of Khiva Abul-Ghazi Khan. Moscow-Leningrad.

Korkyt. (1987). Elim-ai. Almaty: Oner. 
Koroglu, H. (1984). Oghyz heroic epos. Moscow.

Konyratbaev, A. (1991). The history of Kazakh folklore. Almaty.

Konyratbaev, A. (2008). Korkyt baba's book. Astana: Foliant.

Kongyratbay, T. (1996). Monuments of ancient time. Almaty: Oner.

Kongyratbay, T., \& Kongyratbay, K. (2013). Hermeneutical Aspects of Kazakh Heroic Epic Study. Middle-East Journal of Scientific Research (MEJSR), 18(9), 1330-1334. http://dx.doi.org/10.5829/idosi.mejsr.2013.18.9. 12373

Losev, A. et al. (1982). Myths of the world nationa. Moscow.

Marghulan, A. (1975). Poems and legends of ancient time. Almaty

Rashid, al-Din. (1952). Collection of Histories. Saint Petersburg.

Spiridonov, P. (1909). One of the variants of the legend about Korkyt: Protocols from meetings and reports of members of the Turkestan archeologists. Tashkent.

Uspenskij, V., \& Belyaev, V. (1979). Turkmen music. Ashgabat.

Velyaminov-Zernov, V. (1889). Monument to the Arab-Tatar sign in Bashkortostan: Notes of the Eastern Branch of the Russian archeological society. Saint Petersburg.

Zhubanov, A. (1942). Life and works of Kazakh composers. Almaty.

\section{Copyrights}

Copyright for this article is retained by the author(s), with first publication rights granted to the journal.

This is an open-access article distributed under the terms and conditions of the Creative Commons Attribution license (http://creativecommons.org/licenses/by/3.0/). 